\title{
Desenvolvimento Municipal das Microrregiões do Estado do Tocantins: uma análise a partir do Índice Firjan de Desenvolvimento Municipal
}

\author{
http://dx.doi.org/10.21527/2237-6453.2018.45.44-62
}

Recebido em: 12/12/2016

Aceito em: $21 / 11 / 2017$

\section{Ana Lucia Medeiros ${ }^{1}$, Luana Borges dos Santos², Claudomiro Moura Gomes Andre ${ }^{3}$}

\begin{abstract}
RESUMO
Este artigo tem como objetivo analisar o desenvolvimento municipal das microrregiões do Estado do Tocantins e toma como marco temporal os anos de 2000 e 2010, e parte, para tanto, do Índice Firjan de Desenvolvimento Municipal (IFDM). A base teórica leva em conta o pensamento de Amartya Sen, que apresenta um novo olhar sobre o desenvolvimento econômico, entende-o como um processo de expansão das liberdades reais que as pessoas desfrutam com vistas ao atendimento daquilo que desejam. Posto isso, busca-se analisar os dados relativos ao PIB per capita, os gastos públicos nas funções saúde e educação e o Índice Firjan de desenvolvimento municipal. Partindo da tabulação dos dados, foi possível cartografar o desenvolvimento municipal das microrregiões do Estado do Tocantins. O principal achado do trabalho mostra que, ao longo dos dez anos, houve crescimento no indicador de desenvolvimento nos municípios do Tocantins e as dimensões saúde e educação tiveram a maior participação no IFDM.
\end{abstract}

Palavras-chave: Desenvolvimento municipal. Desenvolvimento humano. Liberdades.

\section{MUNICIPAL DEVELOPMENT OF THE MICRO REGIONS IN THE STATE OF TOCANTINS: AN ANALYSIS FROM THE FIRJAN INDEX OF MUNICIPAL DEVELOPMENT}

\begin{abstract}
This article aims to analyze the municipal development of the micro regions in the State of Tocantins, taking as temporal mark the years 2000 and 2010, starting from the Firjan Municipal Development Index - FMDI. The theoretical basis takes into account the thought of Amartya Sen, who presents a new look at economic development, understanding it as a process of expanding the real freedoms that people enjoy in order to fulfill what they want. This analysis aims at analyzing data on GDP per capita, public expenditure on health and education functions and the Firjan index of municipal development, and, based on the tabulation of data, it was possible to map the municipal development of the micro-regions of the State of Tocantins. The main finding of the study shows that over the ten years, there was growth in the development indicator in the municipalities of Tocantins, where the health and education dimensions were those that had the largest participation in the FMDI.

Keywords: Municipal development. Human development. Freedoms.
\end{abstract}

\footnotetext{
${ }^{1}$ Doutora em Administração de Empresas pela Universidade Presbiteriana Mackenzie. Professora da Universidade Federal do Tocantins. analucia@uft.edu.br

${ }^{2}$ Mestre em Desenvolvimento Regional pela Universidade Federal do Tocantins. luana.borges040@gmail.com

${ }^{3}$ Doutor em Genética e Melhoramento pela Universidade Federal de Viçosa. Professor da Universidade Federal do Tocantins.andrecmg@yahoo.com
} 
O conceito de desenvolvimento, na perspectiva econômica, está associado à realização do bem-estar social que, por muito tempo, considerando seus aspectos normativos, recebia o mesmo significado de crescimento econômico. Ao longo dos anos, o conceito foi reelaborado e passou a incorporar variáveis além daquelas relacionadas ao crescimento da riqueza, mas, sobretudo, às diretamente relacionadas com a qualidade de vida da população (OLIVEIRA, 2002). No final do século 20, o tema foi enriquecido pelos estudos do economista indiano Amartya Sen, que defendeu a ideia de que o desenvolvimento é um processo de expansão das liberdades reais que as pessoas desfrutam, e que, por isso, deve-se considerar a qualidade de vida das pessoas e as suas capacitações (SEN, 2000; ESPINOZA; AUGUSTO, 2009). A questão-chave do pensamento de Sen está associada ao bem-estar social, não somente sobre o prisma da coletividade, mas também do individual. Questiona, por exemplo, se a produção de riqueza é condição necessária para garantir o bem-estar das pessoas, uma vez que essa questão, em sua visão, depende da capacidade e das liberdades que as pessoas têm para realizar ações orientadas àquilo que desejam para a vida. Ao assim questionar, entende que o conceito de desenvolvimento, sob a ótica econômica, por si só não garante e não determina o bem-estar social se as pessoas não gozam de suas liberdades individuais, que, em boa medida, estão associadas a questões substantivas e instrumentais.

Enquanto colaborador na criação do Índice de Desenvolvimento Humano (IDH), o pensamento de Sen se colocou como alternativa para se analisar e explicar o desenvolvimento das regiões e dos países. A partir dessa nova perspectiva, o conceito de desenvolvimento humano passou a ser usado para explicar o desenvolvimento dos países. Sen, em sua teoria, destaca a importância das capacitações e das liberdades substantivas como pré-requisitos para o desenvolvimento humano, posto que contribuem para a melhoria do IDH, que procura medir a qualidade de vida das pessoas por meio de indicadores de saúde, de educação e de renda (SEN, 2000). No Brasil, a Federação da Indústria do Rio de Janeiro (Firjan) criou uma metodologia e desenvolveu o Índice Firjan de Desenvolvimento Municipal (IFDM), que tem como objetivo medir o desenvolvimento dos municípios brasileiros a partir de categorias associadas ao conceito de desenvolvimento humano usado por Amartya Sen - renda, saúde e educação. A diferença reside nas variáveis usadas para qualificar as categorias e também na forma de tratamento dos pesos das variáveis na constituição do indicador.

É possível perceber que, nos últimos anos, o Brasil tem apresentado melhoria nos indicadores de desenvolvimento, em especial no Índice de Desenvolvimento Humano Municipal (IDHM), no IFDM e no índice de Gini, que mensura a desigualdade de renda. O Tocantins, como se sabe, é um dos Estados mais jovens da Federação e corresponde ao que era o antigo norte goiano, na época uma região esquecida pelo Estado e não era praticamente beneficiada pelas políticas públicas de natureza tanto federal quanto estadual, colocando-se, pois, como fruto da divisão do Estado de Goiás. Em decorrência da ausência dessas políticas, o Tocantins nasceu com uma forte dependência financeira da União, tendo em vista a necessidade de fortalecer sua infraestrutura e promover seu desenvolvimento socioeconômico.

A concepção de desenvolvimento neste trabalho contrasta com as visões mais restritas acerca do tema, principalmente com aquela que a identifica como sinônimo de crescimento econômico. Nesse sentido, entende-se desenvolvimento "como um pro- 
cesso de expansão das liberdades reais que as pessoas desfrutam" (SEN, 2000, p. 17). Estas, por sua vez, dependem, via de regra, de políticas públicas que promovam geração de emprego e renda por meio da oferta de microcrédito e que garantam seguridade social, saúde e educação. A análise do desenvolvimento municipal das microrregiões do Tocantins é um estudo relevante que poderá servir para se ter melhor compreensão de como as dimensões de emprego e renda (econômico), saúde e educação (sociais) contribuíram com o indicador de desenvolvimento dos municípios do Estado. Considerando que essas variáveis são as usadas na elaboração do indicador de desenvolvimento humano no âmbito municipal, questiona-se: Houve desenvolvimento municipal nas microrregiões do Tocantins ao longo do período 2000/2010?

Diante disso, este trabalho tem como objetivo analisar o desenvolvimento municipal das microrregiões do Estado do Tocantins, considerando os anos de 2000 e 2010 . O indicador usado no estudo foi o IFDM, que é formado pelas dimensões emprego e renda, saúde e educação. Esse indicador é usado como medida de desenvolvimento municipal na mesma perspectiva que o Índice de Desenvolvimento Humano (IDH), que é constituído pelas dimensões renda, educação, habitação e longevidade, como indicador de saúde. Ambos são utilizados como medida de desenvolvimento, sob uma perspectiva que vai muito além do que a literatura econômica tratou no passado recente.

É importante destacar que este artigo não tem o propósito de explorar os fatores determinantes do desenvolvimento municipal das microrregiões do Estado.

\section{LIBERDADES, CAPACITAÇÕES E DESENVOLVIMENTO HUMANO}

O desenvolvimento econômico foi objeto de estudo de vários economistas, sociólogos e outros estudiosos ao longo do tempo e, para o mainstream da Economia, o desenvolvimento estava associado ao crescimento econômico, de modo que o PIB per capita foi, durante décadas, um indicador desse fenômeno. A história recente mostra que o crescimento da riqueza, apesar de necessário, não é condição suficiente para o desenvolvimento de um país e que tampouco se coloca como um processo apenas unidirecional (SACHS, 2003), mas que, ao contrário, está associado a questões de ordem social, cultural e econômica.

Geralmente, as elevadas taxas de crescimento econômico estão associadas à disponibilidade e à combinação de fatores econômicos, como, por exemplo, de capital, trabalho, capacidade empreendedora, tecnologia, educação e instituições. É sabido que o progresso econômico, quando não bem-distribuído, traz consigo a involução de algumas questões sociais, ambientais e econômicas, tal como a má distribuição de renda, que leva ao crescimento da violência, da injustiça social e a todo tipo de mazela social.

Na última década do século 20, pode-se perceber que o desenvolvimento passou a ser analisado por meio de um novo olhar, que coloca o homem como fim desse processo e não como meio (SEN, 2000). O filósofo e economista Amartya Sen compreende que o desenvolvimento pode ser visto como um processo de expansão das liberdades reais que as pessoas desfrutam, de modo que tenham condições de fazer suas escolhas para o que desejam para suas vidas (SEN, 1983, 1999, 2000). As escolhas estão associadas às liberdades desfrutadas pelos membros da sociedade, e liberdades, por vez, dependem das capacitações individuais condicionadas a processos sociais, econômicos e institucionais (SEN, 2000). 
Nessa grelha teórica, aponta-se para o fato de que o processo de desenvolvimento deve mitigar as fontes de privação das liberdades, que são aquelas associadas à pobreza, à tirania e à carência de oportunidades econômicas. Fomentar as liberdades individuais, portanto, é criar condições para que o homem, enquanto indivíduo, tenha autonomia, autodeterminação e empoderamentos social e econômico. Segundo Sen (2000), a garantia das liberdades, como, por exemplo, a de fazer escolhas políticas, a de ter assistência médica e a de receber educação de qualidade, está entre os componentes que constituem o desenvolvimento e, segundo essa perspectiva, percebemos que há um distanciamento em relação àquela que analisa o desenvolvimento em uma direção apenas unidimensional. Compreender esse processo como intrínseco apenas a uma visão utilitarista, é não reconhecer a importância da humanidade e dos valores e dos direitos do ser humano na História das coisas e do mundo. Isso, por sua vez, garantirá ao indivíduo conquistar as capacitações e as habilidades para alcançar algumas condições que façam com que o homem viva a melhor vida que escolheu para si (SEN, 1983, 1999, 2000, 2012). Encontrar um ambiente, portanto, no qual seja possível expandir as liberdades e as capacidades individuais, torna a vida mais rica e desimpedida, assim como pode garantir um espaço mais rico e apto para a promoção do desenvolvimento (SEN, 2012). Segundo Sen (1999, 2000), o Estado, por meio de políticas públicas, e o mercado podem fomentar as capacitações das pessoas, garantindo-lhes seus direitos civis, o acesso à educação básica, à saúde e à oportunidade de ter emprego formal. Entende-se que isso aumenta o potencial das pessoas de cuidarem de si mesmas e, consequentemente, sua capacidade de influenciar positivamente o mundo. A perspectiva do pensamento de Sen sobre desenvolvimento é aquela voltada para o humano, partindo do pressuposto de que, para aferir o bem-estar da população, não se deve considerar apenas a dimensão econômica, mas também outras características, como sociais, culturais e políticas, que influenciam a qualidade da vida das pessoas.

Considerando que o desenvolvimento de um país implica a expansão das liberdades dos indivíduos, Sen (2000) discute os conceitos de liberdades substantivas e instrumentais, compreendendo que as primeiras incluem capacidades elementares, como, por exemplo, ter condições de evitar privações de boa alimentação, a morte prematura, de saber ler e de ter participação política. São, portanto, aquelas que enriquecem a vida e as que se quer atingir como fim. As instrumentais, por seu turno, dizem respeito aos meios para se atingir os fins. Por exemplo, para se ter a liberdade substantiva de saber ler ou conhecer as propriedades da matemática, busca-se a liberdade instrumental de poder frequentar a escola (SEN, 2000; PINHEIRO, 2012). Seguindo essa direção, Sen (2000) elenca cinco tipos de liberdades instrumentais: 1 ) liberdades políticas, como eleições diretas e livre-expressão do pensamento; 2) facilidades econômicas, como participação no comércio e na produção; 3 ) oportunidades sociais e acesso aos serviços de saúde e educação; 4) garantias de transparência; e 5) segurança protetora.

Com essas cinco liberdades instrumentais, as pessoas passam da condição de paciente para a de agente, e podem, assim, efetivamente moldar seu próprio destino e ajudar uns aos outros. Desse modo, deixam de ser vistas apenas como beneficiárias passivas de programas de desenvolvimento para agentes e podem, nessa condição, ajudar no processo de desenvolvimento do país (SEN, 2012). 
A qualidade de vida pode ser em muito melhorada, a despeito dos baixos níveis de renda, mediante um programa adequado de serviços sociais. $O$ fato de a educação e os serviços de saúde também serem produtivos para o aumento do crescimento econômico corrobora o argumento em favor de dar-se mais ênfase a essas disposições sociais nas economias pobres, sem ter de esperar "ficar rico" primeiro (2000, p. 66).

Sob essa perspectiva, o pensamento do autor contraria o modelo de desenvolvimento econômico instituído no Brasil a partir do último quarto do século 20 , em que entrou em cena o pensamento econômico ligado à ortodoxia convencional, cuja perspectiva teórica orbitava em torno de uma agenda neoliberal. A partir dos anos de 1980, a economia brasileira passou por um processo de reestruturação neoliberal em um contexto de democratização política, o que permitiu a liberalização do comércio e o enfraquecimento do Estado, que abriu mão da sua estratégia desenvolvimentista e criou um modelo econômico pautado pelo ajuste fiscal, que não permitiu a expansão do financiamento das políticas públicas, principalmente aquelas de cunho social (BRESSER-PEREIRA, 2012).

Na visão de Sen (2000), a busca pelo desenvolvimento humano gera crescimento econômico a partir do momento em que, na busca pelo primeiro, ocorrem gastos públicos e/ou privados. Nesse caso, o processo de melhorar a vida das pessoas retroalimenta o sistema econômico. Ao defender esse mecanismo, convém destacar que o Estado, ao assumir o protagonismo desse processo, busca não somente a responsabilidade de desenvolver de forma substantiva as pessoas, mas também criar condições para que elas possam ter liberdade, alteridade, autodeterminação e dignidade para assumir o controle da própria vida.

Em suma, o processo que gera o desenvolvimento humano cria oportunidades sociais que contribuem diretamente para a expansão das capacidades humanas e da qualidade de vida. Há evidências de que, com renda relativamente baixa, um país que garante serviços de saúde e de educação a todos pode, efetivamente, obter resultados notáveis no que diz respeito à duração e à qualidade de vida de toda a população, se comparados com países desenvolvidos (SEN, 2000). O Estado, então, pode promover o bem-estar da sociedade por meio do financiamento das políticas públicas, em especial, nas áreas de saúde, de educação e de emprego e renda.

\section{ESTADO E GASTOS PÚBLICOS}

A função básica do Estado é maximizar o bem-estar da sociedade e, para isso, cumpre três importantes papéis: 1) alocar recursos com vistas à produção e à provisão de bens e serviços que atendam à sociedade; 2) distribuir renda, visando a garantir o bem-estar social; e 3) estabilizar a economia, de modo a garantir as condições para o país crescer e se desenvolver (GIAMBIAGI; ALÉM, 2000). Não há consenso na literatura sobre qual deve ser o tamanho do Estado e quais as funções que se deve priorizar para garantir o bem-estar da sociedade. Geralmente mensura-se a participação ou a intervenção do Estado na economia por meio das despesas ou dos gastos públicos realizados pelo governo. 
Os economistas que defendem uma agenda econômica convencional e ortodoxa, cuja orientação é a redução do Estado objetivando manter as contas públicas equilibradas, acreditam que o mercado, ao usar seus mecanismos de autorregulação e de impessoalidade, consegue alocar os recursos de forma mais eficiente, o que beneficiará o conjunto da população (FONSECA; CUNHA; BICHARA, 2013). Por outro lado, há pensadores que aprovam a maior participação do Estado na economia por acreditarem que se pode criar igualdade de oportunidades para toda a população por meio da democratização do acesso à educação, à saúde, à habitação, ao transporte e ao ambiente urbano (SEN, 1999).

Ao fazer isso, cria-se condições para que todos possam ter liberdade para fazer suas escolhas nas mais diversas dimensões. Acredita-se que essas condições devem ser providas para que as pessoas tenham as mesmas oportunidades e possam disputar os recursos no mercado em igualdade de condição (OFFE, 1999).

Compactua-se com a ideia de que o financiamento das políticas públicas, orientadas para o desenvolvimento socioeconômico, garante aos seres humanos o acesso a serviços e bens públicos, dignifica os homens e pode, em médio e longo prazos, criar um ambiente favorável para a promoção do desenvolvimento. No que se refere ao papel do Estado diante da promoção do desenvolvimento, há estudos que mostram que os gastos públicos, especialmente aqueles realizados com as funções agricultura, transporte, saúde e educação, contribuem para o desenvolvimento dos municípios. Segundo Moreira et al. (2013), gastos com saúde e educação foram determinantes para a melhoria do indicador de desenvolvimento dos municípios do Espírito Santo. Os municípios foram agrupados e, a partir de testes estatísticos, foi possível identificar fortes correlações entre os gastos com tais funções e a melhoria do IFDM desses municípios.

Ribeiro et al. (2013) relacionaram os mecanismos de controle social, a exemplo da Lei de Responsabilidade Social, com o desenvolvimento dos municípios em Minas Gerais. Encontraram evidências de que a gestão dos recursos públicos influencia positivamente as variáveis renda e urbanização. Por outro lado, descobriram correlação negativa entre as funções saúde e educação e a gestão dos recursos públicos para os municípios mineiros. O trabalho de Rezende, Slomsky e Corrar (2005) analisa os condicionantes do desenvolvimento humano dos municípios em São Paulo. A partir do modelo utilizado, ficou demonstrado que a relação entre os investimentos públicos e os indicadores de desenvolvimento não é linear. Afirmam também que os municípios que realizaram os maiores investimentos públicos não são aqueles que se fazem presentes nos agrupamentos e que apresentam os melhores indicadores de desenvolvimento.

Varela, Martins e Corrar (2009) estudaram a relação entre o perfil do gasto público e os indicadores sociais dos municípios paulistas e perceberam que os municípios que realizam gastos nas funções sociais - educação e saúde - apresentaram melhores indicadores de desenvolvimento. Brito, Nascimento e Lima (2011) mostraram que os menores indicadores de desenvolvimento humano se encontram em municípios do Norte e do Nordeste e concluíram que, para os municípios dessas regiões, quando há melhoria no componente educação, os acréscimos marginais são mais significativos no IDH do que para o conjunto dos municípios considerados desenvolvidos. Acreditamos, assim, que os gastos públicos nas funções sociais são relevantes para promover o desenvolvimento dos municípios, em especial em regiões historicamente relegadas pelo Estado. 


\section{ÍNDICE FIRJAN DE DESENVOLVIMENTO MUNICIPAL COMO INDICADOR DE DESENVOLVIMENTO HUMANO}

Assim como a Organização das Nações Unidas (ONU) utiliza o IDH para mensurar o desenvolvimento das nações, no Brasil foi criado, pelo Sistema da Federação das Indústrias do Estado do Rio de Janeiro (Firjan), o Índice Firjan, que acompanha o desenvolvimento dos mais de cinco mil municípios brasileiros em três áreas: emprego e renda, educação e saúde. Os dados desses componentes se constituem estatísticas oficiais dos Ministérios do Trabalho, da Educação e da Saúde, com periodicidade anual, recorte municipal e abrangência nacional. Os dados usados em cada dimensão do IFDM estão disponíveis nas bases de dados nacionais com informações da grande maioria dos municípios brasileiros.

Do mesmo modo que o IDH, o IFDM varia de zero a 1. Quanto mais próximo de 1, maior o desenvolvimento do município. Com base nessa metodologia, estipularam-se as seguintes classificações:

a) municípios com IFDM entre [zero e 0,4 ) baixo estágio de desenvolvimento;

b) municípios com IFDM entre $[0,4$ e 0,6$)>$ desenvolvimento regular;

c) municípios com IFDM entre $[0,6$ e 0,8$)>$ desenvolvimento moderado;

d) municípios com IFDM entre $[0,8$ e 1,0) alto estágio de desenvolvimento (FEDERAÇÃO..., 2011).

No cálculo do IFDM, emprego e renda, educação e saúde possuem igual ponderação, dado que o índice é a média aritmética simples destas três dimensões. A Figura 1 mostra quais são as variáveis usadas na elaboração desses atributos.

Figura 1 - Variáveis componentes do IFDM por área de desenvolvimento

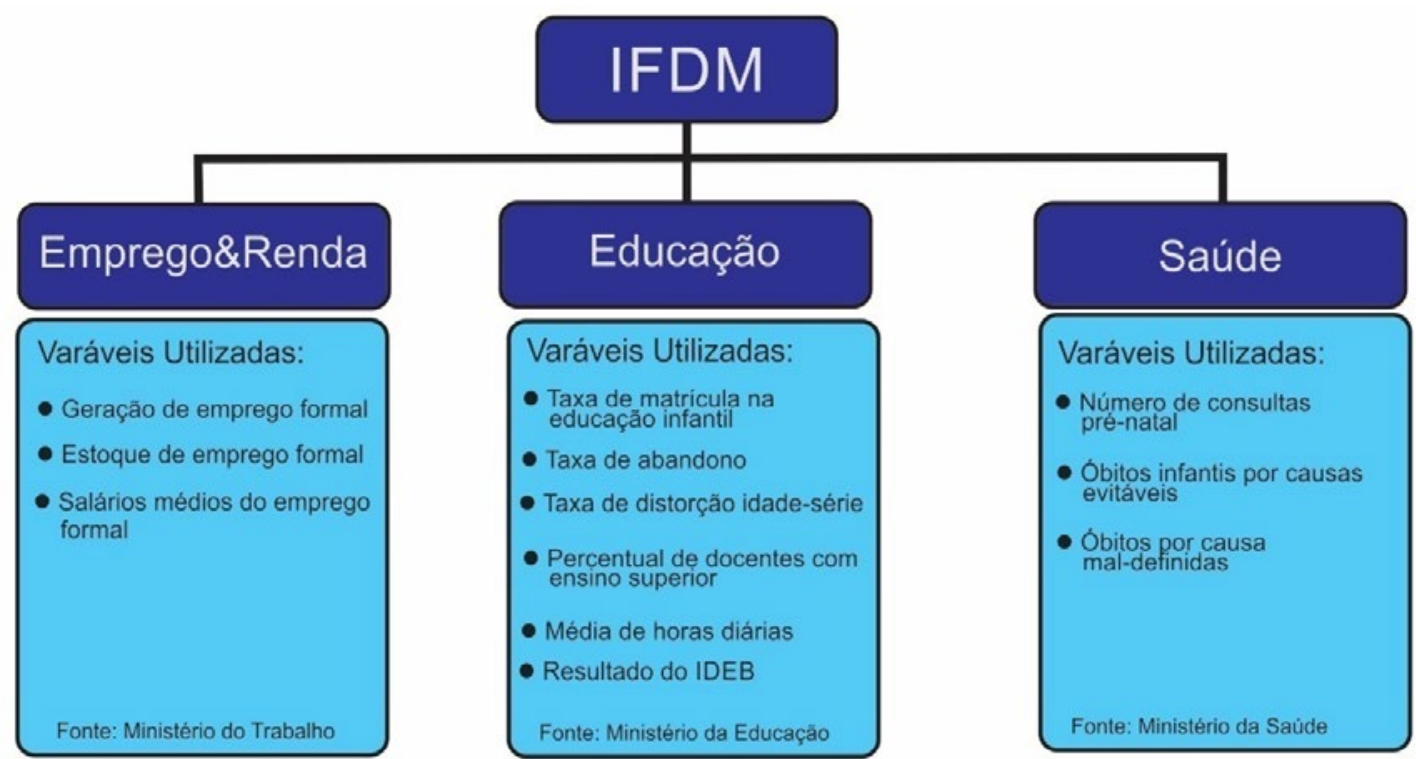

Fonte: Notas metodológicas da Firjan (FEDERAÇÃO..., 2011).

Segundo a metodologia que calculou o IFDM para os anos do estudo (2000 e 2010), o Índice Firjan de emprego e renda é composto por duas dimensões: emprego, que avalia a geração de emprego formal e a capacidade de absorção da mão de obra 
local; e renda, que acompanha a geração de renda e sua distribuição no mercado de trabalho local. Cada uma dessas dimensões representa 50\% do IFDM emprego e renda. 0 IFDM educação é composto por seis indicadores e tem como objetivo captar a oferta de educação infantil e, principalmente, a qualidade da educação fundamental em escolas públicas e privadas. O IFDM saúde tem foco na saúde básica e contempla três indicadores, cujo controle é de competência do poder municipal.

\section{METODOLOGIA}

O Estado de Tocantins possui 139 municípios e foi dividido pelo Instituto Brasileiro de Geografia e Estatística (IBGE) em duas mesorregiões - ocidental e oriental - e em oito microrregiões. A mesorregião ocidental é formada por cinco microrregiões: Araguaína, Bico do Papagaio, Gurupi, Miracema do Tocantins e Rio Formoso e a mesorregião oriental é constituída pelas microrregiões de Dianópolis, Jalapão e Porto Nacional. Os dados utilizados para a realização do presente trabalho foram coletados nos sites oficiais da Firjan e do IBGE, e no que se refere às despesas públicas com saúde e educação consultou-se o site Finanças do Brasil - Finbra (BRASIL, 2012).

No processo de tabulação dos dados foi calculado o quanto cada componente contribuiu para o IFDM de cada município. Além disso, foi observada a evolução do PIB per capita, que está diretamente associada ao componente emprego e renda, à participação do emprego formal por microrregião no total geral criado em Tocantins para os anos de 2007, 2008, 2009 e 2010, como também foi dada atenção a despesas e transferências públicas referentes à saúde e à educação. Para cartografar o desenvolvimento das microrregiões do Tocantins, foram elaborados mapas para representar o IFDM e seus componentes; isso porque permitem que se observe a representação espacial do desenvolvimento nas microrregiões estudadas. Os municípios, no mapa, foram identificados de acordo com seu estágio de desenvolvimento. O IFDM e seus três componentes variam de zero a 1 e são classificados em quatro estágios: baixo estágio de desenvolvimento, desenvolvimento regular, desenvolvimento moderado e desenvolvimento alto.

A Figura 2 mostra o mapa do Tocantins a partir das duas mesorregiões com suas respectivas microrregiões. O desenvolvimento dos municípios do Estado foi cartografado e, a partir disso, foi possível identificar os níveis dos indicadores para o conjunto dos municípios do Tocantins. 
Figura 2 - Mapa do Estado de Tocantins com identificação das duas mesorregiões e de suas respectivas microrregiões

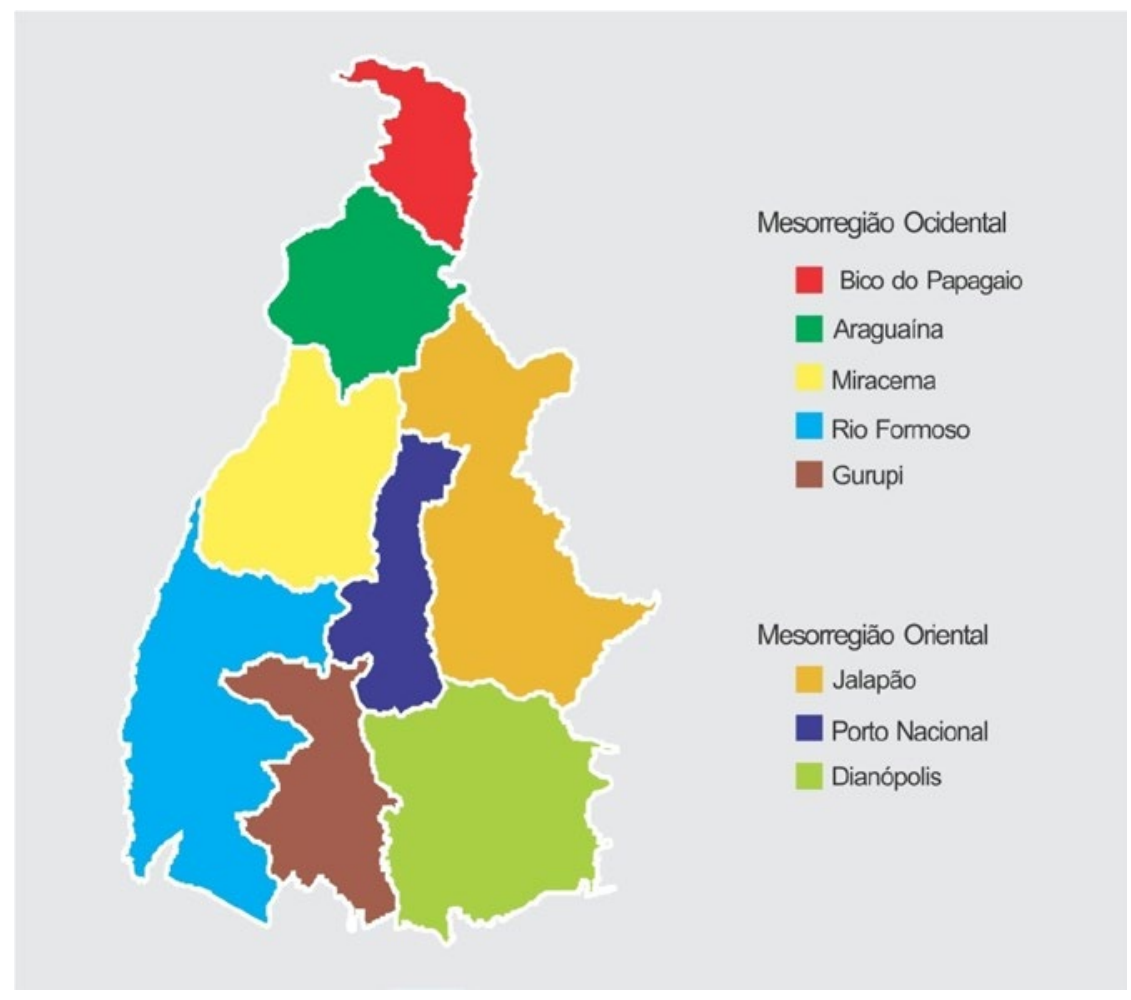

Fonte: INSTITUTO... (2010).

Segundo a metodologia da Firjan (FEDERAÇÃO..., 2011), as fontes dos dados do IFDM emprego e renda são os registros da Relação Anual de Informações Sociais (Rais) e do Cadastro Geral de Empregados e Desempregados (Caged) do Ministério do Trabalho, e projeções oficiais de população do IBGE. A fonte de todos os indicadores usados para calcular o IFDM educação são produzidas pelo Instituto Nacional de Estudos e Pesquisas em Educação Anísio Teixeira (Inep), do Ministério da Educação. Os dados para calcular o IFDM saúde têm como fonte o dataSUS do Ministério da Saúde.

\section{RESULTADOS E DISCUSSÃO}

O Estado de Tocantins foi criado em 1988 e está localizado na região Norte. Além de Palmas, capital do Estado, está divido em outros 138 municípios e, conforme contagem populacional realizada pelo IBGE (INSTITUTO..., 2010), esta era de 1.383.445 habitantes, distribuída em uma área de $277.621 .858 \mathrm{~km}^{2}$. A participação da economia tocantinense no PIB nacional, no referido ano, foi $0,5 \%$ e, na região Norte, $8,3 \%$. Os principais componentes do PIB do Tocantins são: agropecuária: $17,8 \%$, indústria: $24,1 \%$ e serviços: $58,1 \%$ (INSTITUTO..., 2010). Como se pode perceber, o setor de serviços é o principal responsável pela formação do PIB estadual, segmento da economia que se concentra na capital, Palmas, e nas cidades localizadas próximo à rodovia BR-153, posto ser intenso o fluxo de pessoas nessas localidades (SOUZA, 2004).

A agropecuária é a atividade responsável por, aproximadamente, 99\% das exportações no Estado, e a bovinocultura de corte coloca-se como um dos grandes elementos econômicos. O Estado também é produtor agrícola, com destaque para o cultivo 
de arroz, mandioca, abacaxi, cana-de-açúcar, milho e soja. Concernente ao setor industrial, ele está concentrado nas cidades de Palmas, Gurupi, Porto Nacional, Araguaína e Paraíso do Tocantins, e suas principais indústrias são as de produtos minerais (ouro e calcário, borracha e plástico), agroindustrial e alimentícia, cuja produção é destinada notadamente ao consumo interno. Quando observamos a Tabela 1, percebemos que houve crescimento econômico em todas as microrregiões do Estado.

Tabela 1 - Produto interno bruto per capita por microrregião do Estado do Tocantins 2000/2010 (valores correntes em mil reais)

\begin{tabular}{lccc}
\hline \multirow{2}{*}{ Microrregiões } & \multicolumn{2}{c}{ PIB per capita } & \multirow{2}{*}{ Crescimento } \\
\cline { 2 - 3 } & 2000 & 2010 & \\
\hline Araguaína & $3.204,00$ & $5.181,00$ & $61,70 \%$ \\
Bico do Papagaio & $1.511,00$ & $2.822,00$ & $86,76 \%$ \\
Dianópolis & $2.221,00$ & $4.457,00$ & $100,68 \%$ \\
Gurupi & $4.491,00$ & $6.878,00$ & $53,15 \%$ \\
Jalapão & $1.756,00$ & $4.785,00$ & $172,49 \%$ \\
Miracema do Tocantins & $3.057,00$ & $5.845,00$ & $91,20 \%$ \\
Porto Nacional & $4.134,00$ & $7.122,00$ & $72,28 \%$ \\
Rio Formoso & $4.368,99$ & $6.458,98$ & $47,84 \%$ \\
\hline
\end{tabular}

Fonte: INSTITUTO... (2010).

Na primeira década do século 21, com a expansão das fronteiras agrícolas, especialmente para a produção de soja, o Estado tornou-se um centro de atração de investimentos (RODRIGUES; RODRIGUES, 2008). Alguns municípios das microrregiões de Jalapão, Dianópolis e Miracema do Tocantins estão entre os maiores produtores de soja do Estado, e os dados mostram que essas microrregiões foram aquelas em que o PIB per capita mais cresceu. A Tabela 2 mostra os gastos públicos com educação e saúde nos municípios do Tocantins nos anos de 2000 e 2010. Percebemos que houve um decréscimo nos gastos públicos com educação apenas na microrregião de Dianópolis. De modo geral, os gastos com educação e saúde apresentaram um crescimento significativo para os municípios do Tocantins.

Tabela 2 - Gastos públicos com educação e saúde por microrregião do Tocantins 2000-2010 (em mil de R\$)

\begin{tabular}{lrrrrrr}
\hline \multirow{2}{*}{ Microrregiões } & \multicolumn{2}{c}{ Educação } & \multicolumn{2}{c}{ Saúde } & \multicolumn{2}{c}{ Crescimento } \\
& \multicolumn{1}{c}{2000} & \multicolumn{1}{c}{2010} & 2000 & 2010 & Educação & \multicolumn{1}{c}{ Saúde } \\
Araguaína & 15,958 & 96,027 & 11,347 & 77,989 & $501,73 \%$ & $587,29 \%$ \\
Bico do Papagaio & 7,838 & 87,605 & 5,582 & 62,448 & $1017,72 \%$ & $1018,77 \%$ \\
Dianópolis & 46,45 & 44,437 & 19,013 & 37,812 & $-4,34 \%$ & $98,87 \%$ \\
Gurupi & 12,94 & 65,115 & 10,889 & 30,283 & $403,21 \%$ & $178,11 \%$ \\
Jalapão & 8,349 & 36,504 & 4,445 & 22,532 & $337,24 \%$ & $406,93 \%$ \\
Miracema do Tocantins & 13,132 & 64,101 & 8,498 & 55,582 & $388,13 \%$ & $554,04 \%$ \\
Porto Nacional & 21,094 & 148,489 & 20,676 & 123,788 & $603,96 \%$ & $498,70 \%$ \\
Rio Formoso & 10,37 & 47,746 & 8,472 & 37,969 & $360,42 \%$ & $348,18 \%$ \\
\hline
\end{tabular}

Fonte: Finanças Brasil - Finbra (BRASIL, 2012). 
Ao analisar os gastos públicos com educação e saúde nas microrregiões do Estado do Tocantins, nota-se que houve elevação, o que demonstra que, nesse período, o Estado elevou os gastos com políticas sociais cujos resultados estão associados ao conceito de desenvolvimento a partir das liberdades instrumentais e substantivas (SEN, 2000).

As microrregiões do Bico do Papagaio e do Jalapão acumulam um déficit histórico em que se concentravam os piores indicadores socioeconômicos do Tocantins. Ao observamos o crescimento de mais de $1.000 \%$, no decorrer do período em saúde e educação no Bico do Papagaio, que é a maior microrregião (25 municípios), percebemos que poderá surgir a possibilidade de se construir um novo modelo de desenvolvimento, este orientado para a valorização da dignidade humana e das liberdades.

No que diz respeito à dimensão econômica (emprego e renda), salienta-se que as microrregiões de Araguaína, Porto Nacional e Gurupi foram as que geraram o maior número de emprego formal no período de 2007 a 2010, e que apresentaram a maior participação no emprego formal do Tocantins.

Tabela 3 - Participação da criação de empregos formais nas microrregiões do Tocantins em relação ao emprego formal criado no Estado de Tocantins (em porcentual)

\begin{tabular}{lcccc}
\hline \multirow{2}{*}{ Microrregião } & \multicolumn{3}{c}{ Ano } \\
\cline { 2 - 5 } & 2007 & 2008 & 2009 & 2010 \\
\hline Araguaína & 28,46 & 24,36 & 25,37 & 21,68 \\
Porto Nacional & 34,63 & 35,51 & 40,86 & 42,49 \\
Gurupi & 14,07 & 10,14 & 10,65 & 14,35 \\
Bico do Papagaio & 2,33 & 3,98 & 5,01 & 3,53 \\
Miracema & 6,89 & 10,06 & 6,48 & 7,07 \\
Rio Formoso & 6,19 & 7,98 & 7,63 & 7,38 \\
Jalapão & 2,09 & 1,39 & 1,14 & 1,16 \\
Dianópolis & 3,85 & 5,44 & 2,86 & 2,32 \\
\hline
\end{tabular}

Fonte: BRASIL (2017).

Os dados da Tabela 3 mostram que a microrregião de Porto Nacional foi a que apresentou o maior crescimento na participação do emprego formal do Estado de Tocantins, e as microrregiões do Jalapão, Bico do Papagaio e Dianópolis destacaram-se como as que apresentaram a menor participação, uma vez que a base econômica é pouco dinâmica porque não encontraram força motriz que advém de variáveis econômicas, institucionais e de governança, capaz de alavancar o seu crescimento econômico (OLIVEIRA; PIFFER, 2016). As microrregiões de Porto Nacional, Araguaína, Miracema e Gurupi são as que apresentam maior dinamismo econômico em decorrência do corredor econômico criado a partir da construção da BR-153, que foi um fator que atraiu investimentos tanto nas áreas urbanas quanto nas rurais (OLIVEIRA; PIFFER, 2016; OLIVEIRA; RODRIGUES, 2016).

No que respeita aos empregos criados no Estado, no período entre 2007 e 2010 observou-se que foram admitidas 234.130 pessoas no mercado de trabalho formal e 217.555 foram demitidas. Quando se observam esses dados por microrregião, destacam-se Bico do Papagaio, Jalapão e Dianópolis como aquelas em que o saldo de empre- 
go formal foi negativo, ou seja, houve mais demitidos do que admitidos. A microrregião de Porto Nacional foi aquela em que teve o maior saldo de emprego formal - 10.982 empregos (BRASIL, 2017).

\section{Desenvolvimento Municipal das Microrregiões do Tocantins nos Anos 2000 e 2010}

O desenvolvimento municipal mensurado a partir do IFDM aumentou, em média, $2,67 \%$ ao ano no período dos dez anos. Em apenas quatro não houve melhoria do indicador. Tomando como recorte três microrregiões do Tocantins - Jalapão, Porto Nacional e Araguaína -, vê-se que elas apresentaram melhoria do índice em todos os municípios, com um crescimento médio anual igual ou superior a 3,21\%. Em comparação à classificação do nível de desenvolvimento, em nenhum dos 136 municípios com IFDM, em 2010, houve diminuição desse mesmo nível quando se faz a comparação com a classificação feita há 10 anos. Dos 30 municípios que, em 2000, estavam com desenvolvimento baixo, todos melhoraram sua classificação: 25 passaram para regular, 4 para moderado e 1 não foi avaliado. Entre os 107 que, em 2000, foram classificados com desenvolvimento regular, 71 permaneceram com a mesma classificação, 34 ascenderam para moderado e 2 não tiveram avaliação em 2010. Por fim, dos dois municípios com desenvolvimento moderado, um permaneceu no mesmo nível de desenvolvimento e o outro ascendeu para o patamar de alto desenvolvimento municipal.

Os valores do componente emprego e renda dos municípios cresceram a uma taxa média de 3,86\% ao ano - segunda maior taxa de crescimento -, passando de um valor médio de 0,3095, em 2000, para 0,4082, em 2010. Apesar de o aumento considerável ser o componente com menor contribuição para o IFDM entre os três eixos considerados pela Firjan, não se pode desconsiderar que é um avanço. Em 2000, 105 municípios tinham valor inferior a 0,4 (nível de desenvolvimento baixo), 28 com valor entre 0,4 e 0,6 (desenvolvimento regular) e seis municípios com valor entre 0,6 e 0,8 (desenvolvimento moderado). Transcorridos 10 anos, 98 municípios apresentaram crescimento, e 38 mostraram decréscimo no valor do componente. Quando consideramos a classificação do nível de desenvolvimento, em 2010, 54 municípios permaneceram com a mesma classificação de 2000, 62 melhoram a classificação e em 20 municípios o nível de desenvolvimento, em 2010, foi inferior ao observado 10 anos antes.

Entendemos que o governo federal e subnacionais podem contribuir para a garantia das liberdades por meio da realização de gastos públicos nas funções educação, saúde, previdência social, agricultura e infraestrutura, por exemplo. Por meio da Figura 3 é possível observar que os municípios do Tocantins saíram de um patamar, em 2000, com um IFDM predominantemente baixo, 30 municípios, e regular, 107 municípios, para regular, 96 municípios, e moderado, 39 municípios, em 2010. As microrregiões de Bico do Papagaio, Jalapão, Gurupi, Porto Nacional e Araguaína foram as que mais se destacaram em termos de evolução desse indicador.

Podemos inferir que o desenvolvimento municipal dessas microrregiões está associado aos gastos públicos em políticas sociais e à dinâmica econômica dos municípios. Em 10 anos o PIB per capita do Bico do Papagaio cresceu 87\%, como se pôde ver na Tabela 1, e o crescimento dos gastos em educação e saúde cresceram 1.018\% e 1.019\%, respectivamente (Tabela 2). Em 2000, 9 dos 15 municípios da microrregião do Jalapão 
apresentavam indicador de baixo desenvolvimento e, em 10 anos, em todos os municípios da microrregião esse indicador foi classificado como desenvolvimento regular (Figura 3). O PIB per capita da microrregião do Jalapão cresceu $172 \%$ em 10 anos (Tabela 1), enquanto os investimentos públicos em educação e saúde foram de $337 \%$ e $407 \%$, respectivamente (Tabela 2 ).

A Figura 3 mostra que os municípios da microrregião de Gurupi saíram da condição de desenvolvimento baixo e regular e passaram para as faixas de regular e moderado. Conforme os dados mostrados na Tabela 1, o PIB per capita dessa microrregião cresceu em 10 anos o equivalente a 53\%. Apesar de o crescimento econômico ter ficado bem abaixo da maior parte das outras microrregiões, essa microrregião apresentou, em 2010, o segundo maior PIB per capita do Estado. A economia dessa microrregião é orientada para a agricultura e a pecuária, com predominância também de empresas do ramo industrial. No que se refere aos gastos públicos, em 10 anos os gastos com educação foram 502\% maiores em 2010 que em 2000, à medida que para saúde o aumento no mesmo período foi de $587 \%$ (Tabela 2).

Os indicadores de desenvolvimento dos municípios da microrregião de Porto Nacional saíram da condição de baixo, regular e moderado para regular, moderado e alto, respectivamente (Figura 3). No que se refere à produção de riqueza, em 2000, a microrregião apresentava o terceiro maior PIB do Estado e, em 2010, já liderava o ranking entre as microrregiões do Tocantins. O município de Palmas, capital do Estado, se situa nessa microrregião. É possível afirmar que tanto os indicadores econômicos quanto os sociais desse município influenciam positivamente o desenvolvimento de sua microrregião. É o único município que apresentou um alto indicador de desenvolvimento no Tocantins. Em 10 anos (2000/2010) o crescimento no número de empresas no município foi da ordem de $152 \%$, o que culminou na geração de empregos formais que, pela primeira vez, superou a quantidade de empregos estatutários na cidade. Ainda no que se refere ao indicador de desenvolvimento dessa microrregião, é possível atestar que os investimentos públicos em educação e saúde cresceram $604 \%$ e $499 \%$, respectivamente, nos anos de 2000 e 2010 (Tabela 2).

O desenvolvimento municipal da microrregião de Araguaína também apresentou uma significativa evolução na referida década: em 2000, indicadores de desenvolvimento considerados baixo e moderado e, em 2010, elevou os seus indicadores para regular e moderado. O crescimento do PIB per capita, ao longo do período, foi de $62 \%$. Esse é o terceiro menor crescimento entre as microrregiões, porém detém o quarto PIB per capita entre as microrregiões do Tocantins (Tabela 1). Nos gastos públicos em saúde ocorreu o segundo maior crescimento (587\%) entre as oito microrregiões do Estado (Tabela 2). Sob essa mesma perspectiva, nessa microrregião houve crescimento dos gastos com educação, que ficou na ordem de 502\%. 
Figura 3 - Índice Firjan de desenvolvimento municipal IFDM e seus componentes dos municípios do Estado do Tocantins nos anos de 2000 e 2010

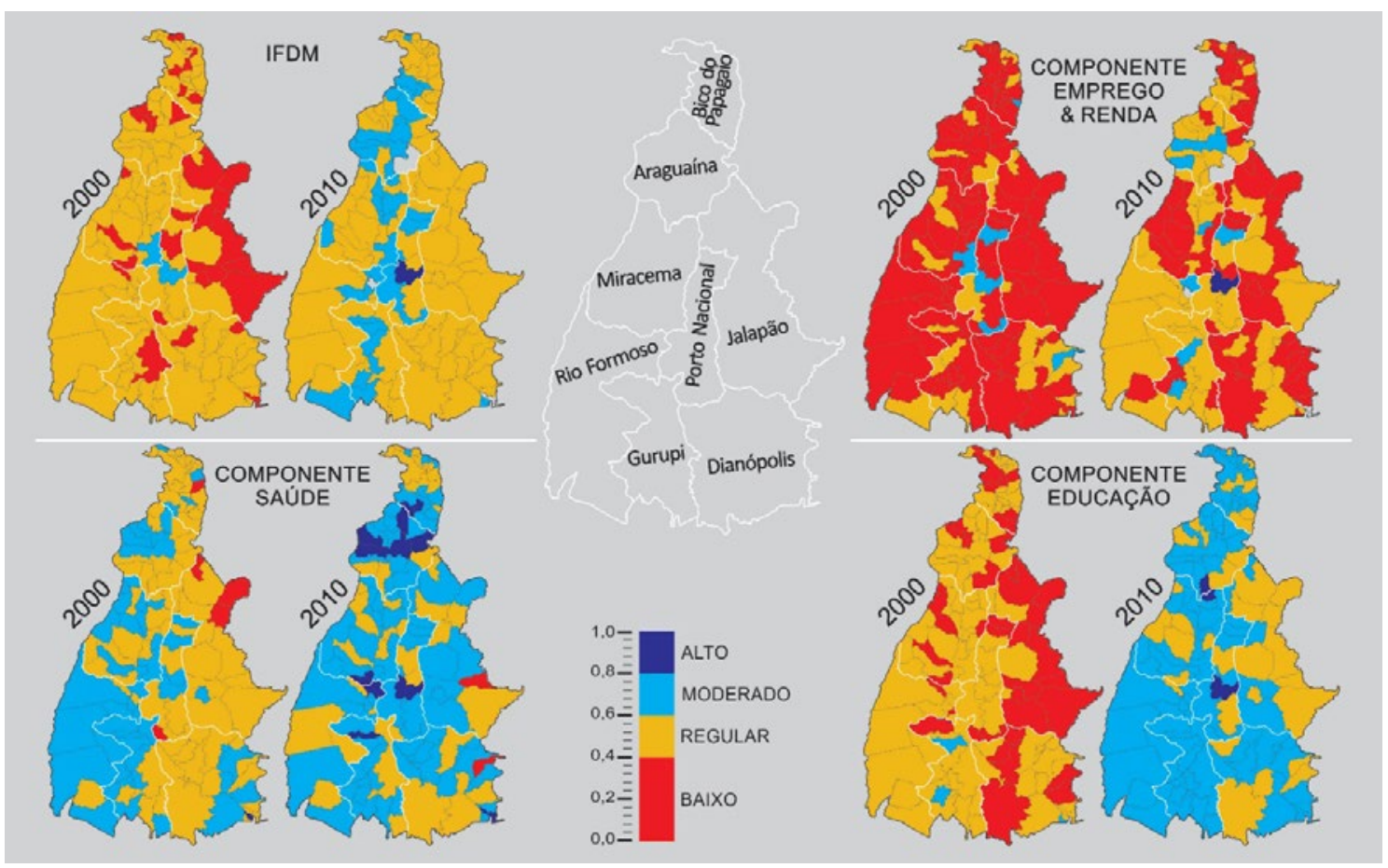

Fonte: Elaboração própria a partir dos dados da Firjan (FEDERAÇÃO..., 2011).

Apesar de não se poder afirmar sobre o que determinou o desenvolvimento dos municípios das microrregiões do Tocantins no interregno de dez anos, é possível afirmar que o aumento no financiamento nas funções sociais, principalmente em educação e saúde, apresentou taxas de crescimento maiores do que as taxas de crescimento do PIB per capita. Apesar de se ter evidências empíricas, elas não permitem considerar que foram apenas os gastos públicos com essas funções que promoveram o crescimento do indicador de desenvolvimento para esses municípios. Há, na literatura brasileira, diversos trabalhos que mostram que os gastos públicos nas funções sociais são determinantes para o desenvolvimento humano dos municípios (MOREIRA et al., 2013). Há também evidências de que a gestão da execução dos recursos públicos guarda relações com os indicadores de desenvolvimento dos municípios (KLERING; KRUEL; STRANZ, 2012). Por outro lado, há trabalhos que sinalizam que os acréscimos marginais são mais impactantes nos indicadores de desenvolvimento nos municípios com baixos indicadores do que naqueles que são considerados desenvolvidos (BRITO; NASCIMENTO; LIMA, 2011).

A elevação dos gastos públicos com saúde e educação nos municípios do Tocantins permite inferir que há uma sinalização de que o Estado está realizando políticas públicas orientadas para o desenvolvimento municipal. Ao analisar a Figura 3, pode-se observar que os componentes de educação e saúde foram os maiores responsáveis pela melhoria dos índices de desenvolvimento municipal das microrregiões do Tocantins. Entre as dimensões do IFDM, o da saúde apresentou um visível crescimento, uma vez que os municípios, em média, saíram de indicadores regulares e moderados para regulares, moderados e altos (Figura 3). No que se refere à dimensão educação, houve um significativo crescimento em todas as microrregiões do Tocantins (Figura 3), e, em boa parte 
dos municípios do Tocantins, em 2000, esse indicador se situava entre baixo e regular. Em uma década passou para moderado e alto, prevalecendo, no entanto, moderado na maior parte dos municípios do Estado.

O componente emprego e renda também apresentou melhoria, porém não na mesma proporção dos outros, tendo em vista que, em 2000, em grande medida, o indicador de desenvolvimento nessa área se situava na faixa baixa e, após uma década, passou, na grande maioria dos municípios, para a faixa regular, mas ainda persiste boa quantidade dos municípios com classificação baixa, principalmente nas microrregiões do Bico do Papagaio, Miracema do Tocantins, Jalapão e Dianópolis. De todos os 139 municípios do Tocantins, em 9 o componente emprego e renda foi o que mais contribuiu para a composição do IFDM em 2000 e, em 2010, em nenhum município esse componente se destacou como a maior contribuição dentre as três dimensões (emprego e renda, saúde e educação), o que mostra que, em 10 anos, a economia do Tocantins apresentou pouco dinamismo e não gerou renda e emprego suficientes para alavancar o desenvolvimento municipal.

A microrregião de Porto Nacional destacou-se como a única no componente emprego e renda, posto que essa dimensão apresentou um crescimento médio de participação na composição do indicador de desenvolvimento em razão dos empregos e da renda gerados na cidade de Palmas, capital do Estado. Em 2010, o indicador dessa dimensão foi de 0,8892, sendo o mais elevado do Estado. Em 10 anos o número de empresas sediadas nesse município cresceu em torno de $153 \%$ e, pela primeira vez, o número de empregados celetistas superou a quantidade de funcionários estatutários (INSTITUTO..., 2010). A Tabela 1 mostrou o PIB per capita de cada microrregião, e seus dados podem ser comparados com os resultados obtidos na Figura 3. A microrregião mais rica é a de Porto Nacional, e a que apresentou menor taxa de crescimento do PIB per capita foi a de Rio Formoso, com 48\%. A microrregião do Bico do Papagaio é a que apresentou menor renda per capita, se levados em consideração os dados relativos tanto ao ano de 2000 quanto ao de 2010. Em 2000 a microrregião do Jalapão era a segunda com o menor indicador de PIB per capita do Estado, mas com a mais alta taxa de crescimento, 172\%. Conseguiu, em 10 anos, ultrapassar a microrregião de Dianópolis, que, mesmo com uma alta taxa de crescimento do PIB per capita, se apresentou como a segunda microrregião mais pobre do Estado em 2010.

É importante destacar que a dimensão emprego e renda está associada diretamente à dinâmica econômica dos municípios e depende de uma série de fatores e não somente da ação do governo. Depende, por exemplo, do mercado de bens e serviços, de fatores de produção, de trabalho, da produtividade do trabalho e do capital, de fatores institucionais e de variáveis macroeconômicas no âmbito interno e externo à região. Ao analisar os dados que compõem o corpus desta pesquisa, coloca-se em discussão a ideia de que as variáveis econômicas pouco contribuíram para a composição do indicador de desenvolvimento dos municípios do Tocantins. Os dados apresentados mostram que é possível promover o desenvolvimento municipal por outras vias e não apenas pelo caminho do crescimento econômico. Esse argumento encontra ancoragem, por exemplo, quando se atenta à Figura 3, que mostra que o IFDM da microrregião do Bico 
do Papagaio, em 2010, está na faixa entre regular e moderado e, em contraposição, o IFDM emprego e renda se encontra na faixa baixo e regular, com forte predominância do baixo.

Ao elevar os gastos com educação e saúde, a União procurou criar um círculo virtuoso na sociedade para que as pessoas pudessem garantir suas liberdades substantivas e instrumentais, seus funcionamentos e capacidades. Ao fazer isso, o Estado, por meio de políticas públicas, orientadas para a promoção do desenvolvimento humano, buscou também garantir o bem-estar individual e social, que pode se traduzir no direito das pessoas de terem liberdades para realizar suas escolhas tanto no campo econômico quanto no social e no político. Pessoas que têm acesso à educação, à saúde e à renda gozam da liberdade para realizar suas escolhas políticas, por exemplo.

Figura 4 - Anéis do desenvolvimento municipal do Tocantins: proporção da população do Estado do Tocantins por faixa de indicador de desenvolvimento municipal e suas dimensões nos anos de 2000 e 2010

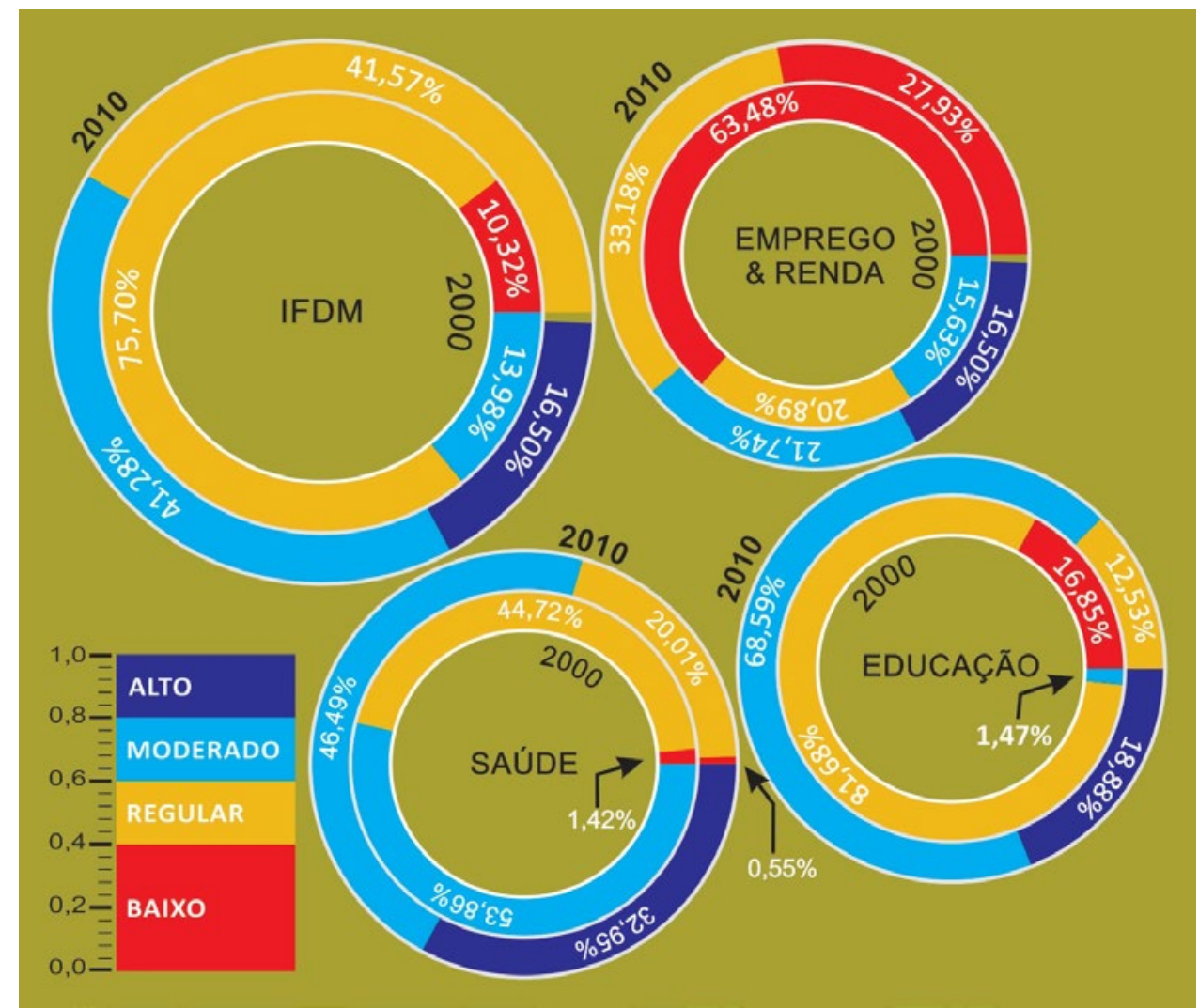

Fonte: Elaboração própria a partir dos dados do IBGE (INSTITUTO..., 2010) e da Firjan (FEDERAÇÃO..., 2011).

A Figura 4 mostra que, em 2000, 75,7\% da população do Estado do Tocantins ocupava espaços onde o indicador de desenvolvimento municipal era regular e 10,3\% onde o IFDM era baixo. Nesse mesmo ano, observa-se também que ninguém residia em municípios com indicador de desenvolvimento alto. Já, em 2010, houve uma redução na proporção da população: $41,57 \%$ dos que viviam em municípios onde o IFDM era regular, enquanto a maior parte da população do Estado passou a residir em municípios cujo desenvolvimento se enquadrava entre a faixa de IFDM moderado e alto. É importante destacar que 16,5\% da população residia em Palmas, capital do Estado, cujo IFDM 
é alto. A mesma Figura mostra que, em 2000 , mais de $80 \%$ da proporção da população do Tocantins residia em municípios com IFDM emprego e renda na faixa de baixo e regular. Em dez anos essa proporção caiu para cerca de $60 \%$ e $16,5 \%$ da proporção da população que reside em Palmas, que tem o IFDM emprego e renda na faixa de alto desenvolvimento municipal.

Pode-se inferir, a partir da apresentação dos dados na Figura 4, que, ao longo de uma década, uma significativa proporção da população do Tocantins passou a residir em municípios que apresentaram melhores indicadores de desenvolvimento. Essa informação pode ser comprovada quando se observam as dimensões do IFDM saúde e educação. Para essas duas, a proporção da população que residia em municípios onde a faixa do IFDM é moderada e alta aumentou de maneira significativa. Observou-se que, em 2010, apenas 0,55\% da proporção da população do Tocantins residia em municípios cujo IFDM saúde era baixo. Isso significa que nesses municípios os atributos da dimensão saúde correspondiam a uma situação em que poderia haver elevados registros de mortalidade infantil e óbitos por causas maldefinidas, além de atendimento inadequado às mulheres que necessitavam de pré-natal. Sabe-se que o Estado deve atuar para minimizar esses problemas, seja por meio de aumento de gastos públicos ou mediante a melhoria na gestão da saúde desses municípios.

No que se refere ao componente educação do IFDM, percebe-se que, em 2010, toda a população do Estado do Tocantins residia em municípios cujas faixas de desenvolvimento se encontravam entre regular, moderado e alto. Os dados produzidos pelo Tesouro Nacional (Finbra) mostram que, em 10 anos, a União aumentou os gastos com educação e saúde em todas as microrregiões do Estado do Tocantins. Não se pode afirmar que os gastos públicos foram determinantes para a melhoria nos indicadores de desenvolvimento municipal nas microrregiões do Tocantins, porém é possível concluir que as dimensões saúde e educação foram aquelas que apresentaram maior participação no desenvolvimento municipal do Estado. Espera-se que se crie no Tocantins um círculo virtuoso em que o desenvolvimento possa se traduzir também em maior crescimento econômico para o Estado. Acredita-se que o sentido do conceito de desenvolvimento está associado à garantia da dignidade humana e à capacidade de oferecer às pessoas, de forma indiscriminada, as mesmas oportunidades; somente assim poderão ter liberdade de fazer suas escolhas nos mais diversos campos - político, econômico e institucional.

\section{CONSIDERAÇÕES FINAIS}

O objetivo deste trabalho foi analisar o desenvolvimento municipal das microrregiões do Estado do Tocantins nos anos de 2000 e 2010 a partir do IFDM, que considera, em sua composição, três variáveis: saúde, educação, emprego e renda. Com a apresentação dos dados, foi possível perceber que, em média, a educação foi a dimensão que mais elevou sua participação na composição do índice, enquanto a dimensão saúde continuou, desde 2000 até 2010, sendo, em média, o que mais contribuiu na composição do índice, ou seja, no desenvolvimento dos municípios. Pode-se afirmar que os gastos públicos nas funções saúde e educação apresentaram crescimento ao longo da década e que podem explicar a melhoria dos indicadores de desenvolvimento municipal do Tocantins. 
Como visto, o estudioso Amartya Sen entende, diferentemente do pensamento econômico ortodoxo, que uma região não precisa vir a ser muita rica para começar a investir no desenvolvimento humano, isto é, em saúde, educação, emprego e renda, posto que, mesmo em regiões pobres, o custo de se oferecer tais serviços é relativamente barato. Dito isso, não é difícil sustentar que a microrregião mais rica não é necessariamente a mais desenvolvida, e a mais pobre, igualmente, a que possui o menor índice de desenvolvimento humano, caso em que se mostra inválido o pensamento de que "é preciso crescer economicamente para depois promover o desenvolvimento humano". Nessa linha de raciocínio, não constitui garantia a lógica de que uma região, logo depois de crescer economicamente, promoverá o desenvolvimento das pessoas, investirá na saúde, na educação, no saneamento básico e em habitações dignas.

Além da riqueza da microrregião, é necessário, pois, mensurar a qualidade de vida da população, e é exatamente isso que o IFDM busca fazer ao considerar, em seu cálculo, as dimensões educação, saúde, emprego e renda, dado que as duas primeiras variáveis sociais mostram que uma microrregião ou um município não precisa apresentar um elevado PIB para ter elevados índices de desenvolvimento. É o caso do município de Crixás do Tocantins, que possui o menor PIB do Estado do Tocantins e, no entanto, ocupa a sexta posição quando se considera o indicador de desenvolvimento do Tocantins. Outro aspecto relevante desta pesquisa diz respeito aos dados dos gastos públicos realizados nas funções saúde e educação, sobre as quais não se pode concluir que as políticas públicas a elas direcionadas foram as responsáveis pela elevação do indicador de desenvolvimento dos municípios do Tocantins. Não se pode afirmar se elas foram determinantes para a elevação do IFDM do Estado, o que se considera uma limitação deste estudo.

Para futuros trabalhos, destaca-se a necessidade de estudar quais os fatores determinantes do IFDM nos municípios do Tocantins, bem como o que determinou o desenvolvimento dos municípios que ocupam o espaço central na direção norte/sul representado na Figura 3. Pode-se pressupor que lá se encontram os principais municípios do Tocantins que são margeados pelo Rio Tocantins e estão nas cercanias da BR-153, que é a principal estrada federal que corta todo o Estado. Como as variáveis econômicas tiveram pouca participação nos indicadores de desenvolvimento dos municípios, supõe-se que outros fatores, que não os econômicos, foram responsáveis pelo seu desenvolvimento.

\section{REFERÊNCIAS}

BRASIL. Finanças do Brasil: dados contábeis dos municípios. Disponível em: <http://www.tesouro.fazenda.gov.br/estatistica>. Acesso em: 10 out. 2012.

Perfil do município. Disponível em: <http://bi.mte.gov.br/bgcaged/caged_perfil_municipio/index.php>. Acesso em: 10 jul. 2017.

BRESSER-PEREIRA, L. C. Do antigo ao novo desenvolvimentismo na América Latina. In: DELORME PRADO, Luiz Carlos (Org.); D’AGUIAR, Rosa Freire (Ed.). Desenvolvimento econômico e crise. Rio de Janeiro: Contraponto Editora, 2012.

BRITO, M. A.; NASCIMENTO, J. S.; LIMA, J. E. de. Diferenciais de desenvolvimento econômico entre os municípios brasileiros: uma análise sob o prisma da regressão quantílica. In: CIRCUITO DE DEBATES, 1., 2011, Brasília: Ipea; Code, 2011.

ESPINOZA, B.; AUGUSTO, G. Sen y algunos escritos en la constitución del campo del desarrollo humano. Polis: Revista de la Universidad Bolivariana, Santiago, v. 8, n. 23, p. 413-26, 2009. 
FEDERAÇÃO DAS INDÚSTRIAS DO ESTADO DO RIO DE JANEIRO (Firjan). Índice Firjan de Desenvolvimento municipal - IFDM 2009. Rio de Janeiro: Firjan, 2011.

FONSECA, P.; CUNHA, A.; BICHARA, J. O Brasil na era Lula: retorno ao desenvolvimentismo? Nova Economia, v. 23, n. 2, p. 403-428, 2013.

GIAMBIAGI, F.; ALÉM, A. C. Finanças públicas. 2. ed. Rio de Janeiro: Campus, 2000.

INSTITUTO BRASILEIRO DE GEOGRAFIA E ESTATÍSTICA (IBGE). 2010. Disponível em: <www.ibge.gov.br/catálogos/indicadores>. Acesso em: 11 set. 2012.

KLERING, L. R.; KRUEL, A. J.; STRANZ, E. Os pequenos municípios do Brasil: uma análise a partir de índices de gestão. Análise - Revista de Administração da PUCRS, v. 23, n. 1, p, 31-44, 2012.

MOREIRA, R. L. et. al. Relevância dos gastos públicos na determinação do desenvolvimento municipal no Estado do Espírito Santo. In: ENCONTRO DA ANPAD, 37., 2013, Rio de Janeiro. Anais... Rio de Janeiro: Anpad, 2013.

OFFE, C. A atual transição da história e algumas opções básicas para as instituições da sociedade. In: PEREIRA, L. C. B.; WILHEIM, J.; SOLA, L. (Org.). Sociedade e Estado em transformação. São Paulo: Unesp; Brasília: Enap, 1999.

OLIVEIRA, G. B. Uma discussão sobre o conceito de desenvolvimento. Revista FAE, Curitiba, v. 5, n. 2, p. 37-48, maio/ago. 2002.

OLIVEIRA, N. M.; PIFFER, M. Conjuntura do desenvolvimento regional dos municípios do Estado do Tocantins. Desenvolvimento Regional em Debate, v. 6, n. 3, p. 32-61, nov. 2016.

OLIVEIRA, T. J. R.; RODRIGUES, W. O passado e o presente no território tocantinense: uma abordagem histórica dos grupos populacionais. Desafios: Revista Interdisciplinar da Universidade Federal do Tocantins, v. 2, n. 2, p. 138-154, jan./jul. 2016.

PINHEIRO, M. M. S. As liberdades humanas como bases do desenvolvimento: uma análise conceitual da abordagem das capacidades humanas de Amartya Sen. In: Ipea. Texto para discussão (1794). Rio de Janeiro, nov. 2012.

REZENDE, A. J.; SLOMSKI, V.; CORRAR, L. J. A gestão pública municipal e a eficiência dos gastos públicos: uma investigação empírica entre as políticas públicas e o Índice de Desenvolvimento Humano (IDH) dos municípios do Estado de São Paulo. Revista Universo Contábil, Blumenau, v. 1, n. 1, p. 24-40, jan./abr. 2005.

RIBEIRO, C. P. P. et al. A influência da Lei de Responsabilidade Fiscal nos indicadores socioeconômicos dos municípios mineiros. In: ENCONTRO DA ANPAD, 37., 2013. Rio de Janeiro. Anais... Rio de Janeiro: Anpad, 2013.

RODRIGUES, S. C. S.; RODRIGUES, W. Estimativa do valor econômico de reservas ecoturísticas na Amazônia Legal: o caso do Jalapão, Estado do Tocantins. Amazônia: Ci. \& Desenv., Belém, v. 3, n. 6, jan./jun. 2008.

SACHS, I. O tripé do desenvolvimento includente. Palestra magna. In: SEMINÁRIO DE INCLUSÃO SOCIAL NO BNDES, Brasília, set. 2003. Disponível em: <www.bndes.gov.br/inclusão>. Acesso em: 12 out. 2015.

SEN, A. A ideia de justiça. Coimbra: Almedina, 2012.

Desenvolvimento como liberdade. São Paulo: Companhia das Letras, 2000.

Liberty and social choice. The Journal of Philosophy, v. 80, n. 1, p. 5-28, jan. 1983.

The possibility of Social Choice. The American Economic Review, v. 89, n. 3, jun. 1999.

SOUZA, S. M. Belém-Brasília: abrindo fronteiras no Norte Goiano - atual Tocantins - 1958-1975. In: GIRALDIN, O. (Org.). A (trans)formação histórica do Tocantins. 2. ed. Goiânia: UFG, 2004.

VARELA, P. S.; MARTINS, G. A.; CORRAR, L. J. Perfil dos gastos públicos versus perfil econômico-social dos municípios paulistas. RCO - Revista de Contabilidade e Organizações, - Fearp/USP, v. 3, n. 5, p. 80-97, jan./abr. 2009. 